\title{
LAS HABILIDADES INTERPERSONALES PARA LA NEGOCIACIÓN SEGÚN EL ESTILO DE VIDA Y EL NIVEL OCUPACIONAL EN EMPRESAS PRODUCTORAS DEL PERÚ
}

\author{
Interpersonal skills for the negotiation by the lifestyle and occupational \\ level in industry production of Peru \\ MILdRed T. Paredes ${ }^{1}$ \\ Universidad Nacional Mayor de San Marcos, Lima, Perú \\ (Recibido el 30/04/2011 - Aceptado el 13/06/2011)
}

\begin{abstract}
RESUMEN
En el presente trabajo indagamos sobre la siguiente interrogante: ¿Las habilidades interpersonales para la negociación difieren según los Estilos de vida y de los niveles ocupacionales de los actores en empresas productoras, en Lima, Perú? La población intencional la constituyen los trabajadores estables que desempeñan los cuatro niveles ocupacionales de cuatro empresas privadas productoras peruanas en Lima, Perú. Esta es una investigación aplicativa no experimental, transversal y descriptiva comparativa. Los datos fueron recolectados con el Cuestionario de Habilidades para la Negociación (CHNC2008), con validez de 0.85 y el Inventario Monofactorial del Estilo de Vida, validez de 0.90, fue revisado y reducido (2006) para el estudio, de autoría de Luis Vicuña Peri y Héctor Hernández Valz. La prueba de Kruskall Wallis y la U de Mann Withney se aplicó para la comparación intergrupos, al nivel de significación no mayor del 0.05 en la contratación de la hipótesis por la distribución no normal de los datos de las habilidades para la negociación de conflictos para cada uno de los cuatro Estilos de vida y de los cuatro niveles ocupacionales.

Llegamos a la conclusión que la habilidad interpersonal para la negociación difiere significativamente según los Estilos de vida adquiridos y por el nivel ocupacional de la población en empresas productoras en el Perú.
\end{abstract}

Palabra clave: Estilo de vida, habilidades de negociación, tipos de estilo de vida, nivel.

\begin{abstract}
This raises interpersonal skills for negotiation differ between Lifestyle and Occupational levels of actors in production companies, in Lima, Peru? The population intentional, consisting of stable workers who perform the four occupational levels of four private companies producing in Peru in Lima, Peru. Applied investigation non-experimental and descriptive cross-sectional comparative study on data collected with the Questionnaire for the Negotiation Skills (CHNC-2008), validity of 0.85 and the Inventory Monofactorial Lifestyle, validity of

1 Profesora Asociada de la Facultad de Psicología de la UNMSM.

E-maill: mparedest@unmsm.edu.pe / mildredparedestarazona@gmail.com
\end{abstract}


0.90, as revised and reduced (2006) for the study, written by Vicuña, Luis and Hernández, Héctor. The Kruskal Wallis and Mann Whitney U was applied for intergroup comparison, the significance level no greater than 0.05 in the testing of the hypothesis by the not normal distribution of data from the Skills for the negotiation of conflicts for each one of four Lifestyle and four levels in employment.

Conclusion: Interpersonal skills for negotiation differs significantly depending on the acquired lifestyles and occupational level of the population of manufacturing companies in Peru.

Keywords: Lifestyle, negotiation skills, types of lifestyle, occupational level, types of interpersonal negotiation skills.

\section{INTRODUCCIÓN}

Las organizaciones, por ser contextos sociales construidos y calificados por relaciones humanas de diversa cualidad, generan en su interior interacciones que por la naturaleza propia del trabajo conllevan una tensión, evidente y necesaria, la que puede devenir usualmente en conflicto por aquellos roces, acrecentados por la búsqueda, posesión o dominio de recursos. Estos últimos cobran mayor significación por ser escasos y por el deseo de posesión mediado por motivaciones, procesos cognoscitivos, el logro de estatus y específicamente la percepción de la desigualdad en la distribución de recursos, aun cuando se trate en la designación de recursos por la gerencia, a la actividad de la unidad desempeñada en la organización, la que es percibida como no equitativa o importante.

De ahí que prevalece socialmente la atribución al poder que ejerce el recurso, tanto por la percepción del estatus que otorga su acceso o posesión como aunado al impacto en las relaciones humanas por la priorización de motivaciones para la generación en el conflicto interpersonal y social, entre los actores de la organización especialmente por los intereses antagónicos a pesar de que ellos puedan percibir el objetivo de la empresa en común y ser acrecentado o potencializado por problemas socio-económicos, políticos y culturales por ser un sistema interrelacionado con su entorno.

Desde una perspectiva personal y grupal, los problemas propios de diferentes comportamientos económicos, entre ellos, los que el país enfrenta referido al desempleo, a los niveles de calidad de vida por debajo de los índices, se constituyen problemas no aislados, puesto que, en una organización ninguna individualidad o grupo de referencia es ajena a dicho contexto macroeconómico. Tanto el colaborador que asume o administra riesgos o aquel participante que asume posiciones al desempeñar una de las diversas tareas y funciones que se estructuran en la organización. Al asumir la persona, el estatus del rol ejecutivo, profesional o técnico, administrativo u obrero, comunica la ubicación, responsabilidades, logros y poder según la posesión ocupacional que accede en el nivel ocupacional de la jerarquía organizacional.

En la estructura organizacional, cada quien en el nivel socio-organizacional de la jerarquía tiene potestad, disposición o evasión de enfrentar conflictos como el de enfrentar o evadir problemas y buscar o elegir su solución según la cultura organizacional pautado por sus normas de comportamiento de dicho contexto y la intervención de la personalidad de cada colaborador, planteada como la estrategia aprendida que va reestructurando a lo largo 
de la vida, empleada de manera no consiente para lograr sus metas o enfrentar la vida, manteniendo un eje central, el medio-fin, que sustenta el Estilo de vida.

Esta estrategia identificada como Estilo de vida, se constituye en el proceso mediador fundamental que intencionalmente de manera no consciente, según Adler, orienta de modo peculiar para afrontar o solucionar las situaciones, dificultades, problemas o retos como es un conflicto suscitado tanto por la discrepancia de intereses o por la manera de haber aprendido a actuar, tal es el caso al desempeñar una categoría ocupacional. Argumento que también refiere Katona, G. (1965) principalmente a los papeles sociales: "El individuo tiene un papel y una función diferente, según el grupo al que pertenece. No debe esperarse que el individuo se comportará de la misma manera en diferentes situaciones de grupo", como son los roles que se asumen por la posición lograda u otorgada en la jerarquización de la organización, y por las preferencias individuales sobre las cuales se basan la conducta y las tendencias económicas, las que no cambian frecuentemente y de súbito, se dan por cambios en el medio de las personas, en su situación y en sus oportunidades, así como por las capacidades y tendencias en sus predisposiciones psicológicas en la toma de decisiones, y la manera cómo actúan ante un conflicto, teniéndose aquella postura que sustenta la negociación en la forma de desescalamiento entre las partes o actores, la que conducirá a la solución del conflicto Kriesberg, Louis (1975), expresado en: "yo gano - tú ganas".

Requiriéndose para ello habilidades interpersonales para la negociación adquiridas en los contextos primarios la familia y secundarios los laborales u organizacionales propiciadas por las prácticas familiares y de la gestión empresarial, respectivamente. Práctica incluyente al tener la negociación, como estrategia de solución de conflictos, posibilitando construir condiciones de climas organizacionales saludables para el desempeño de sus actores que les posibilitará enriquecer la personalidad o estilo de vida.

Demandando aprendizaje y ejercicio de habilidades interpersonales para la negociación durante la convivencia laboral. Su empleo como capacidad para demostrar competencia luego experticia se hace necesario que en el contexto laboral por ejercicio del poder en los diferentes niveles ocupacionales de la estructura organizacional, se dé la convivencia expresada en relaciones interdependientes. Condición propicia en el otorgamiento de autoridad para la asunción de responsabilidad con libertad en cada función de la organización y la consecución de sus objetivos, propiciantes y coadyuvantes para el fortaleciendo del "sentimiento de comunidad" Adler, A. (1938), estado propio para el desarrollo sustentable.

Por tanto conocedores que sector empresarial productivo orientado al desarrollo sostenible en un mercado competitivo, donde su norte está centrado en la calidad de su producto y la salud de sus actores denominados colaboradores, se quiere indagar en tanto y cuánto ¿Las habilidades interpersonales para la negociación difieren según los Estilos de vida y los niveles ocupacionales de los actores en empresas productoras, en Lima, Perú? emplean sus colaboradores que desempeñan las posiciones de los 4 niveles ocupacionales las habilidades interpersonales para la negociación y cómo según el estilo de vida se diferencian o relaciona con ellas, al ser este un mediador estable constituido desde la infancia y sujeto al moldeamiento continuo de las experiencias de vida, tal como es el mundo laboral por su estructuración. Marcando diferencia las categorías sociales del nivel ocupacional de todo sistema social organizacional en comportamientos diferenciados por estatus, competencias, 
ejercicio del liderazgo, toma de decisiones y modos de solución de conflictos mediante la negociación de manera privilegiada como responsabilidad en el afronte en vías de lograr sus objetivos empresariales. Complementariamente se consideran oportunas las siguientes Interrogantes que explicaran la naturaleza de la problemática en estudio:

A. ¿Las habilidades interpersonales para la negociación son mayores en el estilo de vida Activo Agresivo Objetivo que en el estilo de vida Pasivo Regresivo Apelativo y el nivel ocupacional de los actores en la empresa productora en Lima, Perú?

B. ¿Las habilidades interpersonales para la negociación son mayores en el estilo de vida Activo Agresivo Objetivo que en el estilo de vida Pasivo Regresivo Distanciado y el nivel ocupacional de los actores en la empresa productora en Lima, Perú?

C. ¿Las habilidades interpersonales para la negociación son mayores en el estilo de vida Activo Agresivo Destructivo que en el estilo de vida Pasivo Regresivo Apelativo y el nivel ocupacional de los actores en la empresa productora en Lima, Perú?

D. ¿Las habilidades interpersonales para la negociación son mayores en el estilo de vida Pasivo Regresivo Apelativo que el estilo de vida Pasivo Regresivo Distanciador y el nivel ocupacional de los actores en la empresa productora en Lima, Perú?

\section{Objetivo}

Determinar el nivel de habilidades interpersonales para la negociación según el Estilo de Vida y el nivel ocupacional de los actores en empresas productoras de Lima, Perú.

Objetivos específicos:

1. Comparar el nivel de habilidades interpersonales para la negociación en la población de las empresas productivas según el nivel ocupacional entre el estilo de vida Activo Agresivo Objetivo y el estilo de vida Pasivo Regresivo Apelativo.

2. Comparar el nivel de habilidades interpersonales para la negociación en la población de las empresas productivas según el nivel ocupacional entre el estilo de vida Activo Agresivo Objetivo y el estilo de vida Pasivo Regresivo Distanciador.

3. Comparar e niveles de las habilidades interpersonales para la negociación en la población de las empresas productivas según el nivel ocupacional entre el estilo de vida Activo Agresivo Destructivo y el estilo de vida Pasivo Regresivo Apelativo.

4. Comparar el nivel de las habilidades interpersonales para la negociación en la población de las empresas productivas según el nivel ocupacional entre el estilo de vida Pasivo Regresivo Apelativo y el estilo de vida Pasivo Regresivo Distanciador.

\section{Importancia y Justificación de la Investigación}

Al tener presente que la gestión organizacional debe estar presta a servir a la humanidad, por el nivel interacción que tiene la organización de vincular a la persona con el medio sociocultural, ambiental y ecológico. Sentimos este reto de enfrentar con urgencia, a 
partir de la psicología organizacional elaborar, en un primer momento, el conocimiento y su instrumentación para luego transferir a las organizaciones e instituciones, como la empresa, quien mediante su gestión está invocada a lograr óptimos índices de calidad de vida de sus colaboradores. Si el Estilo de vida es el dinamizador permanente en la socialización, construido y desarrollado en ella, y actúa a nivel no consciente mediante formas o estrategias para enfrentar, solucionar, lograr metas de la vida e imprime en el comportamiento el sello característico de una determinada y estable forma de actuar; como propiciar su modificabilidad, Adler hacia 1937, mediante programas de educación básica dirigidos a formar o coadyuvar al desarrollo o enriquecimiento del Estilo vida propuesto por Adler, A. en Vicuña, L y colaboradores (2000) y teniendo a la negociación como un valor propio de la cultura andina, Paredes, M \& Gonzáles del Rio, C (2000102) Gonzáles del Rio, C \& Paredes, M(1999). Encontramos que el nivel ocupacional desempeña determinando intencionalmente las conductas tanto por especificaciones del puesto normadas en su jerarquía respectiva del nivel ocupacional y además de otorgar estatus, trae o conjuga el conflicto en la organización al presumirse por la desigualdad en la distribución de recursos.

La organización se constituye en medio de modificabilidad del Estilo de Vida en la vida adulta, y para el aprestamiento de las habilidades interpersonales para la negociación; cuyo conocimiento aunará a su manejo o mejora de la solución de discrepancias o conflictos entre unidades productivas y ahondar en el fortalecimiento de puestos de calidad con la repercusión en la calidad de vida de sus actores mediante la implementación de habilidades de negociación y se pueda instituir la norma de la cultura organizacional.

De igual importancia tiene para la gestión de los Procesos de Recursos Humanos, dando paso a la investigación en el tema en la psicología social organizacional. se considera importante la habilidad interpersonal para la negociación en una relación interpersonal dialogante sobre una situación en conflicto, constructo teórico que no tiene antecedentes en nuestro país, aun cuando la evidencia estudios que lo apuntalan como un factor importante para el éxito, las habilidades, entre ellas describen las habilidades emocionales, referidas como habilidades para las relaciones interpersonales, aquellas que "mide la habilidad para dirigir las emociones, la competencia y las habilidades sociales” (Escurra, 2000: 76).

\section{Limitaciones de la Investigación}

No se han estudiado los factores generadores de conflicto de los niveles ocupacionales jerarquizados en las empresas productoras; así como de problemas y división entre miembros de la organización; también vistos como motivo de prejuicio, exclusión u opción de estatus de clase; $y$ tampoco el porqué inducen a la desigualdad en la distribución de recursos. Los resultados se pueden considerar taxativos a la población del estudio ejecutado, sólo empresas productoras del Perú, que por disposición y colaboración a la investigadora han dado acceso a sus contextos empresariales. Sólo se han estudiado las habilidades interpersonales de la negociación, no así las habilidades cognitivas como memoria, pensamiento, lógica, inteligencia, importantes para la negociación, pero, a pesar de ello, nos acerca a nuestra realidad empresarial, pues sin el conocimiento de aquellas, sería aún más limitado, escaso o nulo, como es el caso actual. 
Sólo se ha llegado a describir y comparar la relación, pero no se tendrá la explicación del potencial del efecto, descripción, y sin explicar el proceso de su construcción del tipo de Estilo de Vida. Alcances que nos proporcionará el método clínico y el diseño longitudinal.

\section{Definición de términos básicos de la investigación}

Habilidad Interpersonal para la negociación: Es la destreza o capacidad para hacer algo: motor, verbal o conceptual en una relación interpersonal dialogante sobre una situación en conflicto.

Nivel Ocupacional: Categoría ocupacional tipificada según la estructura del sistema social de la organización. Caracterizada por indicadores: educación, conocimientos, habilidades, competencias, remuneración, responsabilidad, estatus y poder.

Estilo de vida: Es la unidad, configuración y orientación de la personalidad particular de cada sujeto. Es un término amplio que engloba: a) actitudes y comportamientos del individuo construidas y desarrolladas en su infancia; b) opiniones sobre sí mismo, de otros y de la vida que tiene el individuo; c) orientación particular que tiene cada persona hacia la perfección y a la superación de los sentimientos de inferioridad, d) la totalidad y unidad final de cada individuo; y e) de actuación a nivel no consciente a fin de lograr sus metas.

\section{Investigaciones referentes al tema de investigación}

En la naturaleza de una empresa entendida como "construcción social de la realidad y como tal un producto creativo humano”, De Miguel, C. J. Ma. (1999, 2001) se producen una gama de interacciones que califican la modalidad o estilo de gestión, percibida en el clima organizacional, producto en gran medida del proceso del ejercicio del poder entre los más significativos en la compleja estructura organizacional. También al no estar exenta de generarse la conducta de conflicto en el contexto social suscitada en toda convivencia, interacción humana enmarcada por la realidad específica del nivel ocupacional, dada por la división de tareas y la disposición de recursos escasos como por la toma de decisión.

Se aborda la habilidad interpersonal para solucionar el conflicto según cómo el colaborador ha aprendido y acuñado su estilo de vida y le proporciona su aprestamiento de acuerdo al nivel ocupacional que desempeña en la jerarquía organizacional. Al respecto en la búsqueda de estudios relacionados a las variables que son de interés como eje central a la temática: el Estilo de vida según Adler, Niveles Ocupacionales y las Habilidades para la negociación, explorada en la teoría de la Psicología, Administración, Antropología y Sociología, preferentemente ha posibilitado plantear el marco teórico que sustenta el presente estudio.

Se fundamenta que la negociación como conducta de solución de conflictos, también como norma emitida en el comportamiento organizacional, lo cual implica como requerimiento las Habilidades interpersonales para la negociación, así como la prevalencia y la significación como mediador construido al Estilo de vida en la conducta observada en el logro o adquisición de la posición en el nivel ocupacional desempeñado. Importancia de identificar dichos requisitos en el pronóstico para la gestión de los recursos humanos 
y para el desarrollo organizacional, generación de saludables climas organizacionales, enriquecimiento de la cultura organizacional a propósito del bienestar laboral.

Al estar vinculadas las habilidades interpersonales para la negociación con el clima organizacional, condiciones de trabajo y cultura organizacional, son observables en el comportamiento organizacional. Del mismo modo la organización es un medio donde se genera una gama de interacciones desde la dependencia a la interdependencia que se describen en los Estilos de vida Pasivo Regresivo Apelativo a generarla por los Activos Agresivos Objetivos; de la seducción a la destrucción descritos en la manera afrontar que presentan en los Estilos de vida Pasivo Regresivo Distanciador a tenerlo el Activo Agresivo Destructivo.

En la estructura organizacional, el nivel ocupacional es una categoría que tiene la atribución de dar connotaciones significativas en el comportamiento organizacional, por una serie de razones entre ellas por el empleo de sus habilidades y competencias.

Katzenstein, B. en 1932 observa que un trabajador "que va desempeñado una tarea, lo hace según los estilos ocupacionales presentes en los actos de todo individuo durante el curso de su trabajo cotidiano, otorgándole una manera peculiar" peculiaridad denominada en la década de los noventa como know how; lo que hace o marca la diferencia a un producto. Estudio que muestra que durante el desempeño cotidiano de dos empleados con igual resultados obtenidos en sus evaluaciones, logrados en datos cuantificados en marcas hechas según el protocolo de los tests de capacidad aritmética, asociativa, lingüística y motora, de concentración, información y juicio profesional, y con aquellos de igual eficacia en su trabajo, podían resultar enteramente diferente en su manera de trabajar este fundamento le permite aseverar como Estilo a Allport, G. (1961, 506-508) para referir que en el comportamiento económico de una organización: "no había dos individuos cuyos estilos de trabajo fueran iguales y en ningún caso ningún test corriente ni ninguna combinación de tests pone manifiesto el estilo.

Robbins, S. (1994, 477) señala que por regla general, en una mesa de negociación sobre la cantidad de concesiones hechas por el opositor serán menos que las del negociador, pero existe una tendencia general a que el opositor iguale al negociador en cuanto a la frecuencia de las concesiones; así una cantidad significativa de argumentos débiles suelen diluir los argumentos sólidos, tal cual resultados en la conducta para negociar expuesto como resultado del estudio de N. Rackham llevada a cabo por 1976.

Antonioni, D. (1998) encontró la relación positiva significativa entre Tesón con el estilo de Negociación Colaborativa, gana-gana, en la solución de conflictos; en cambio se presenta una relación negativa con el estilo de negociación de Evitación; realizada en una muestra de 351 estudiantes universitarios con una muestra de 120 supervisores.

Solf, Z. A. G. (2004-142) concluye al contrastar la hipótesis "Las variables Orientación de Meta y Tesón cumplen un rol moderador en el modelo motivacional de Hachman y Oldham, de manera que las relaciones entre características del Puesto y las variables Motivación Intrínseca y Satisfacción Laboral varían según el tipo de Orientación Meta o la dimensión de la variable Tesón" estudio en una muestra de 228 trabajadores del sector fabril textil. Precisando que la orientación a la meta es cognitivo. 
Ten Velden, F.; Beersma, B. \& De Dreu, C. (2007) con el objetivo de examinar cómo afecta a la motivación social y la influencia de la minoría en la mayoría en las negociaciones. Muestran como resultados que la norma en virtud de la unanimidad y que las decisiones de los socios minoritarios bloquean en perjuicio del grupo, sólo cuando la minoría tiene motivación hacia sí mismo. Bajo el gobierno de la mayoría, los miembros de esta se unen a expensas de la minoría, haciéndolo únicamente cuando la mayoría tiene una motivación hacia sí mismos. Muestra de 97 grupos de universitarios, 3 personas cada uno, diseño experimental. Sus implicancias son para la investigación sobre la negociación y la toma de decisiones en grupo de discusión.

Los resultados de Kathleen O’Connor, Josh Arnold y Ethan Burris (2005) muestran que las experiencias del pasado tienen un papel para influir en los resultados negociados posteriores.

Jared Curhan y Alex Pentland (2007) examinaron y concluyeron que la dinámica de la conversación que ocurre dentro de los primeros cinco minutos de una negociación puede predecir resultados negociados a partir de la percepción de "dar rebanadas finas" o de tener una "actuación sutil" tenida durante dicho espacio de tiempo.

\section{Habilidades interpersonales para la negociación}

Organización Mundial de la Salud (OMS) hacia 1993 plantea que las habilidades para la vida son "habilidades que le permiten a la persona enfrentar en forma efectiva las exigencias y desafíos de la vida diaria, a través de comportamientos adaptables y positivos", aunando con conclusiones del análisis de M. Grañeras y A. Parras (2008: 291) que las mencionadas habilidades deben considerarse en planes de los programas de formación enfocados en el desarrollo psicosocial, por considerarse integrales, en tanto vienen incluidos en el paracurriculum la habilidad para la solución de conflictos, y las técnicas de mediación y negociación.

El aprendizaje orientado a lograr o adquirir habilidades eficaces de negociación, se fundamenta, cuando Luthans, F. (2008: 270-274) señala que la negociación ha pasado del campo de las relaciones industriales al primer plano de las habilidades administrativas, dando pie a la importancia de las estrategias de negociación según la cultura, mediante la calidad de habilidades de negociación para lograr el éxito personal y organizacional.

Desde la teoría administrativa se formula que el conflicto organizacional e interpersonal en el seno de las organizaciones se presenta con aspectos positivos y negativos para el comportamiento organizacional, entre otros autores señalado por Walton, 1973, Deutsch, 1973, Black y Mouton, en 1961, quienes a propósito de la socialización organizacional identifican las conductas de:

- Desacuerdos interpersonales, sobre "cuestiones substanciales, como diferencias sobre estructuras, políticas y prácticas organizacionales”.

- Antagonismos interpersonales, esto es, "diferencias más personales y emocionales que las anteriores, que surgen entre seres humanos interdependientes”. 
Llevando precisar que no se puede evitar el conflicto pero se puede desarrollar capacidades, a propósito de hacer posible una permanencia grata y productiva en los sistemas sociales como es la empresa, de la misma manera se aprende los conflictos como a ser conflictivos, posibilita fundamentar que se desarrollaran habilidades para solucionarlos, con la característica que sea un producto, la solución del conflicto, un indicador de la vida adulta y no neurótica Vicuña P., Luis y colaboradores (2008: 183-200). Entre dichas capacidades se ubican las habilidades para la negociación, entendidas también habilidades para la vida, describiéndose las siguientes habilidades interpersonales para la negociación planteadas por los autores indicados:

1. Habilidades de comunicación: Capacidad para la decodificación y codificación de códigos: figurativas, simbólicas semánticas y conductuales observadas en cómo se escucha, cómo se responde gestual y posturalmente, cómo se responde verbalmente, situación que ocasiona la reacción verbal o no verbal ante un conflicto en una mesa de negociación.

Mostrada en el proceso de interacción al identificar la capacidad manifiesta en saber escuchar y tener claridad de lo que se trata durante el diálogo entablado.

2. Habilidades de compromiso: Capacidad para involucrarse con la solución del conflicto, se ubica como aquella que debe tener en cuenta que la solución de un conflicto mediante la negociación contempla la necesidad no de perseguir intereses individuales, sino de identificar su responsabilidad social en involucrase con la ayuda social a ser resuelto como propio.

3. Habilidades de control emocional: Capacidad mostrada en identificar la postura ante los ataques en la mesa de negociación, manteniendo el humor o alegría en pos de lograr el objetivo. Observado en el manejo de su rictus o expresiones faciales y corporales.

4. Habilidades de perspectiva: Capacidad mostrada en identificar la naturaleza del conflicto visualizado a partir del ahora, la solución del problema y reconstruye la orientación de la postura o situación a partir de terceros; es decir cómo ve estas cosas desde el punto de vista de los otros.

5. Habilidades de empatía: Capacidad para abandonar sus puntos de vista y asumir en cada instante los puntos de vista de la persona o las personas en conflicto, es decir ponerse en la situación de otro(a) equilibrando los intereses de la organización.

\section{Estilos de vida}

La unidad del Estilo de vida que individualiza, según la Psicología Adleriana, mantiene que tanto lo consciente como lo inconsciente, lo cognitivo, lo emocional, lo conductual, lo psicosomático y lo motivacional, regido por los mismos fines o metas finales de manera unitaria y que su aparente contradicción son solo formas distintas de alcanzar por distintos medios los mismos fines.

De ahí que el estudio de la persona debe regirse por el estudio hacia sus fines o intenciones, y no por la disección de la persona en esferas particulares (lo inconsciente, lo cognitivo, 
lo emocional, etc.) por cuanto el sujeto mediante la experiencia activa consigo mismo y con el entorno va configurando su estilo de vida que se orienta hacia el fin o ideal. Encontrándose que cada individuo según su estilo de vida, es movido o impulsado por los fines que lo identifican, actuando como una brújula inconsciente y que acciona como una búsqueda permanente de algo que en el plano consciente no existe en el momento que se da la conducta (distinto de la conducta a propósito de las metas y de los éxitos que diseña o planifica en el plano consciente del sujeto). Siendo el estilo de vida como aquella condición para la emisión de la conducta según como ha aprendido a obtener sus objetivos, es decir su plan o estrategia que no está a nivel consciente y le resulta favorable a sus intereses, necesidades, inquietudes, deseos. Por tanto la conducta está orientada por la intencionalidad y el Estilo de vida da la estrategia de la intencionalidad.

Constituyendo el complejo medio fin, expuestos en los diversos proyectos del plan de vida según los medios apropiados acorde al contexto tal como la posición que ocupe o desempeñe en el sistema social, en dos categorías principales:

1. Complejo medios-fin pasivo-regresivo: emplean métodos pasivos y regresivos de seguridad existencial; presentan la tendencia distanciadora o tratan de alcanzar el objetivo optando posturas de apartamiento de los problemas.

2. Complejo medios-fin activo-agresivo: los individuos emplean métodos agresivos y proactivos para su seguridad existencial.

La acción con que se actúa el estilo de vida no necesariamente es producto de la lógica (racionalidad), sino del plano no consciente del que hablábamos, así tendremos a la negociación surgida como respuesta ante un problema a propósito de un objetivo individual o social, es decir el modo instalado en la persona para la solución de conflictos implantada como estrategia del estilo de vida.

Alfred Adle planteó el constructo Estilo de vida hacia 1907 y en 1912, consigna su carácter integral y modificable del Estilo de vida aún en el adulto (1937). Permitiendo asumir que Adler desarrolló su modelo psicológico centrado en las influencias del medio social y familiar en el carácter del sujeto en conjunción con sus propias construcciones subjetivas de sus experiencias. Esta presunción describe al "Estilo de vida" rector del psiquismo humano a nivel inconsciente que lo va vinculado permanentemente como integrante solidario de la comunidad universal.

Una vez formado el Estilo de vida se mantiene por diversos procesos mentales, destacando entre ellos el de la "selectividad" de las experiencias, proceso que le faculta a confirmar o rechazar aquellas experiencias cuando no encajan con su Estilo de vida. De ahí, las percepciones del individuo, la valoración que hace de los hechos y de sus emociones y del cómo su conducta está guiada por su Estilo de vida, el que podemos tipificar a partir de M. Titze (1983). Ver Tabla 1. 
TABLA 1. Resumen Medios-Fin para el Estilo de Vida

\begin{tabular}{|c|c|c|c|c|}
\hline $\begin{array}{l}\text { Estilo de Vida } \\
\text { Indicador }\end{array}$ & $\begin{array}{c}\text { Activo Agresivo } \\
\text { Objetivo }\end{array}$ & $\begin{array}{c}\text { Activo Agresivo } \\
\text { Destructivo }\end{array}$ & $\begin{array}{c}\text { Pasivo Regresivo } \\
\text { Apelativo }\end{array}$ & $\begin{array}{l}\text { Pasivo Regresivo } \\
\text { Distanciado }\end{array}$ \\
\hline Actividad & $\begin{array}{l}\text { Modifica para } \\
\text { mejorar }\end{array}$ & Intenta cambiar & Hay pasividad & $\begin{array}{l}\text { No cambia aún } \\
\text { le perjudique }\end{array}$ \\
\hline Agresividad & $\begin{array}{l}\text { Enfrentamiento al } \\
\text { problema }\end{array}$ & $\begin{array}{l}\text { Enfrenta los } \\
\text { problemas }\end{array}$ & $\begin{array}{c}\text { Retroceso, elabora } \\
\text { síntomas evasión, } \\
\text { excusas }\end{array}$ & $\begin{array}{c}\text { Evasión, elabora } \\
\text { síntomas de lástima } \\
\text { para protección. }\end{array}$ \\
\hline Objetividad & Dirigido al logro & $\begin{array}{c}\text { Métodos } \\
\text { violentos Destaca } \\
\text { participación }\end{array}$ & $\begin{array}{c}\text { Apela a otros } \\
\text { resuelvan } \\
\text { problema, "llanto" }\end{array}$ & $\begin{array}{c}\text { Alejamiento físico } \\
\text { y psicológico, } \\
\text { "puerco espín" }\end{array}$ \\
\hline Interés Social & $\begin{array}{c}\text { Acciones a mejorar } \\
\text { el medio }\end{array}$ & $\begin{array}{l}\text { Moderado } \\
\text { mayormente } \\
\text { egoísta }\end{array}$ & $\begin{array}{l}\text { Deteriorado, } \\
\text { asegura la atención } \\
\text { de los otros }\end{array}$ & $\begin{array}{l}\text { Profundo deterioro, } \\
\text { completo desinterés }\end{array}$ \\
\hline Autonomía & TD por sí mismo & $\begin{array}{l}\text { Prima necesidades } \\
\text { emocionales }\end{array}$ & $\begin{array}{c}\text { Dependiente a TD } \\
\text { de otros }\end{array}$ & $\begin{array}{l}\text { Sin acción } \\
\text { autodirigida }\end{array}$ \\
\hline $\begin{array}{l}\text { Solución de } \\
\text { Problemas }\end{array}$ & $\begin{array}{l}\text { Mediante diálogo y } \\
\text { comunicación }\end{array}$ & $\begin{array}{l}\text { Mediante fuerza, } \\
\text { imposición }\end{array}$ & $\begin{array}{l}\text { Solicita ayuda } \\
\text { de otros }\end{array}$ & $\begin{array}{l}\text { Renuncia total } \\
\text { a solución }\end{array}$ \\
\hline $\begin{array}{l}\text { Relaciones } \\
\text { Interpersonales }\end{array}$ & $\begin{array}{l}\text { Genera } \\
\text { interdependencia }\end{array}$ & $\begin{array}{l}\text { Genera } \\
\text { interdependencia }\end{array}$ & Dependiente & Renuncia total \\
\hline $\begin{array}{l}\text { Autoimagen } \\
\text { Estereopercepción }\end{array}$ & $\begin{array}{l}\text { Positiva } \\
\text { Positiva }\end{array}$ & $\begin{array}{l}\text { Positiva } \\
\text { Negativa }\end{array}$ & $\begin{array}{l}\text { Negativa } \\
\text { Positiva }\end{array}$ & $\begin{array}{l}\text { Negativa } \\
\text { Negativa }\end{array}$ \\
\hline Fórmula: Expresión & $\begin{array}{l}\text { "Yo estoy bien- } \\
\text { Tú estás bien" }\end{array}$ & $\begin{array}{l}\text { "Yo estoy bien- } \\
\text { Tú estás mal" }\end{array}$ & $\begin{array}{l}\text { "Yo estoy mal - } \\
\text { Tú estás bien" }\end{array}$ & $\begin{array}{l}\text { "Yo estoy mal - } \\
\text { Tú estás bien" }\end{array}$ \\
\hline
\end{tabular}

* Elaborado por la autora.

\section{El nivel ocupacional}

Está asociado a la posición laboral desempeñada (Katz y Kahn, 1995), cuyas actividades o conductas constituye el papel que va a cumplir. Nivel que está incorporado a un sistema con influencias en la satisfacción y al clima organizacional (Chruden y Sherman,1979).

T. Parsons (1960), desde la perspectiva funcional, plantea que la organización se instituye en cuatro niveles, según la demanda de los roles o funciones desempeñados en la naturaleza intrínseca de la actividad laboral:

Nivel administrativo: Es la que define el nivel administrativo de la organización.

Nivel técnico: Es la responsable de procesar el producto. 
Nivel directivo: Competente de movilizar y coordinar las diversas partes que componen la organización.

Nivel institucional: Conecta a la organización con el sistema que la rodea.

Para el enfoque sistémico las organizaciones pueden caracterizarse como:

Sistemas físicos o concretos; cuando están compuestos por equipos, por maquinaria y por objetos y cosas reales. Y pueden ser descritos en términos cuantitativos de desempeño.

Sistemas abstractos; cuando están compuestos por conceptos, planes, hipótesis e ideas. Aquí, los símbolos representan atributos y objetos, que muchas veces sólo existen en el pensamiento de las personas.

Sistemas abiertos; son los sistemas que presentan relaciones de intercambio con el ambiente, a través de entradas (insumos) y salidas (productos). Estos intercambian materia y energía regularmente con el medio ambiente, suelen ser eminentemente adaptativos, ya que para sobrevivir deben reajustarse constantemente a las condiciones del medio.

D. Katz y R.L. Kahn (1995: 500) desarrollaron un modelo de organización más amplio y complejo, mediante la aplicación de la teoría de sistemas y la teoría de organizaciones, específicamente más el "marco metateórico"

Subsistema psicosocial: está compuesto por individuos y grupos en interacción. Dicho subsistema está formado por la conducta individual y la motivación, las relaciones del status y del papel, dinámica de grupos y los sistemas de influencia.

Subsistema técnico: se refiere a los conocimientos necesarios para el desarrollo de tareas, incluyendo las técnicas usadas para la transformación de insumos en productos.

Subsistema administrativo: relaciona a la organización con su medio y establece los objetivos, desarrolla planes de integración, estrategia y operación, mediante el diseño de la estructura y el establecimiento de los procesos de control.

Asumiendo que en cada subsistema, encontramos que se desempeñan los 4 niveles ocupacionales con prevalencia significativa a su actividad, instituida para responder las exigencias, requerimientos de los usuarios y consumidores, se clasifica en los siguientes Niveles Ocupacionales: 1) Ejecutivo: Gerente, Directivo, Jefe; 2) Profesional: Especialista, Técnico, Consultor; 3) Administrativo: Oficina, Trámite documentario o bancario u otros y 4) Obrero: Obrero calificado, operario.

\section{Hipótesis general:}

La habilidad interpersonal para la negociación difiere significativamente según los estilos de vida adquiridos, y el nivel ocupacional de la población de empresas productoras en el Perú.

\section{Hipótesis específicas:}

$\mathrm{H}_{1}$ : La habilidad interpersonal para la negociación de la población de empresas productoras en el Perú con estilo de vida Activo Agresivo Objetivo es significativamente mayor que el estilo de vida Pasivo Regresivo Apelativo.

$\mathrm{H}_{2}$ : La habilidad interpersonal para la negociación de la población de empresas productoras 
en el Perú con estilo de vida Activo Agresivo Objetivo es mayor que el estilo de vida Pasivo Regresivo Distanciador.

$\mathrm{H}_{3}$ : La habilidad interpersonal para la negociación de la población de empresas productoras en el Perú con estilo de vida Activo Agresivo Destructivo es mayor que el estilo de vida Pasivo Regresivo Apelativo.

$\mathrm{H}_{4}$ : La habilidad interpersonal para la negociación de la población de empresas productoras en el Perú con estilo de vida Activo Agresivo Distanciador es mayor que el estilo de vida Pasivo Regresivo Distanciador.

\section{MÉTODO}

Estudio no experimental, transversal, con el diseño descriptivo comparativo, que permite explorar y describir cómo se comportan variables, según Roberto Hernández, Carlos Fernández-Collado \& L. Pilar Baptista (1997).

Población: La constituyen las Organizaciones empresariales productoras privadas, del sector industrial que han estado dispuestas a colaborar, con la participación de sus integrantes, en la condición de estables y que desempeñan los 4 Niveles Ocupacionales:

Ejecutivos, Profesionales, Administrativos y Obreros dispuestos a responder los Cuestionarios. De ahí la población de empresas productoras del sector industria: Laboratorio Farmacéutico Unido (LUSA); AMFAVITRUM S.A. Metal Metálica (HAUG); y AJEPER S.A.; localizadas en Lima, Perú. Teniendo como Unidad de observación: cada empresa. Obsérvese en la Tabla 2.

TABLA 2. Composición de la Muestra del personal evaluado en empresas productoras

\begin{tabular}{lccccc}
\hline $\begin{array}{l}\text { Empresa/ Nivel } \\
\text { Ocupacional }\end{array}$ & $\begin{array}{c}\text { AJEPER } \\
\text { S.A. }\end{array}$ & HAUG & LUSA & $\begin{array}{c}\text { AMFA } \\
\text { VITRUM }\end{array}$ & $\begin{array}{c}\text { Total } \\
\text { General }\end{array}$ \\
\hline Directivo o Jefe & 11 & 4 & 3 & 8 & 26 \\
Profesional o Técnico & 19 & 25 & 5 & 13 & 62 \\
Administrativo & 10 & 10 & 3 & 15 & 38 \\
Obrero Calificado & 6 & 44 & 22 & 12 & 84 \\
Obrero u Operario & 39 & 63 & 26 & 33 & 161 \\
\hline Total General & 85 & 146 & 59 & 81 & 371 \\
\hline
\end{tabular}

* Elaborado por la autora. 


\section{Relación de Variables}

Variables atributivas: Independiente Asignada, Dependiente y de Control, son susceptibles de observarse en la realidad y con variación al medirse, según Fernández, S; Roberto y Cobradores (2007,123-124). El tipo de variables pueden ser empleadas en aquellos estudios que no se necesitan realizar o demostrar la causa Kerlinger, Fred, N. y Lee, Howard B. (2002, 42).

\section{Variable Independiente Asignada}

Estilo de Vida: Activo Agresivo Objetivo; Activo Agresivo Destructivo; Pasivo Regresivo Apelativo; Pasivo Regresivo Distanciador.

Nivel Ocupacional: Ejecutivo: Gerente; Directivo; Jefe; Profesional: Especialista, Técnico, Consultor; Administrativo: Oficina, Trámite documentario o bancario u otros: Obrero: Obrero calificado, operario.

\section{Variable Dependiente}

Habilidad Interpersonal en la Negociación: Habilidad de Comunicación; Habilidad de Compromiso; Habilidad de control emocional; Habilidad de perspectiva; Habilidad de empatía; Habilidad Interpersonal en la Negociación Eficiente General.

\section{Variable Control}

Empresas productoras industriales localizadas en Lima, Perú.

\section{Técnicas e instrumentos de recolección de datos}

La Versión Revisada y Reducida del Inventario Monofactorial de Complejos MediosFin (IMEVRR-2006) elaborada en 1991 por Luis Vicuña Peri y Héctor Hernández Valz. Instrumento que cuenta con validez de contenido por criterio de jueces y Confiabilidad mayor de 0.90 por el método de la consistencia interna y de 0.88 por el método de testretests. La confiabilidad por escalas es muy alta y alta:

1. ${ }^{\text {era }}$ Escala de Activo Agresivo Objetivo (AAO) (r 0,87)

2. ${ }^{\text {da }}$ Escala de Activo Agresivo Destructivo (AAD). (r 0,92)

3. ${ }^{\text {ra }}$ Escala de Pasivo Regresivo Apelativo (PRA). (r 0;85)

4. ${ }^{\text {ta }}$ Escala de Pasivo Regresivo Distanciador (PRD) (r 0,88)

Cuestionario de Habilidades para la negociación del conflicto (CHNC-RR 2008), tiene validez de contenido y confiabilidad, con significación de cada factor en relación al total, corroborado con los resultados en la Tabla 3 a los presentados en la versión original de Vicuña y col. (2008: 182-200). 
TABLA 3. Correlaciones inter subtest y test total del test de Habilidades para la gestión en la negociación del conflicto revisión efectuada por Mildred Paredes (2008)

\begin{tabular}{lcccccc}
\hline Habilidades & Comunicación & Compromiso & Perspectiva & $\begin{array}{c}\text { Control } \\
\text { Emocional }\end{array}$ & Empatía & $\begin{array}{c}\text { Test } \\
\text { Total }\end{array}$ \\
\hline Comunicación & 1 & & & & \\
Compromiso & $0.55^{*}$ & 1 & & & & \\
Perspectiva & $0.50^{*}$ & $0.36^{*}$ & 1 & & & \\
Control & $0.53^{*}$ & $0.48^{*}$ & $0.33^{*}$ & 1 & & \\
Emocional & $0.49^{*}$ & $0.53^{*}$ & $0.41^{*}$ & $0.46^{*}$ & 1 & \\
Empatía & $0.84^{* *}$ & $0.76^{* *}$ & $0.69^{* *}$ & $0.74 * *$ & $0.76^{* *}$ & 1 \\
\hline Test Total & & & & & &
\end{tabular}

(*) $\mathrm{P}<0.001$

(**) $\mathrm{P}<0.0001$

\section{RESULTADOS}

\section{Los estilos de vida plantean diferencias en las habilidades de negociación}

Mediante el análisis estadístico de la prueba Ji cuadrado, se ubica que un valor de 60.927, con 4 grados de libertad, y siendo la probabilidad que dicho valor se deba al azar menor que 0.0001 , se rechaza la hipótesis nula, confirmándose la hipótesis que afirma que los estilos de vida plantean diferencias en las habilidades de negociación.

\section{El factor de la habilidad de negociación plantea diferencia según el Estilo de Vida}

Resultados observados en la Tabla 4 en los factores: a) Factor habilidad de Comunicación, b) Factor habilidad de Involucramiento, c) Factor habilidad de Control Emocional, d) Factor habilidad de Perspectiva, e) Factor habilidad de Empatía. Se describe que los Estilos de Vida Activo Agresivo Objetivo plantean diferencia en dichas habilidades para la negociación con el Estilo de Vida Activo Agresivo Destructivo, Estilo de Vida Pasivo Regresivo Apelativo, Estilo de Vida Pasivo Regresivo Distanciado. No así, hay diferencia entre los estilos: Estilo de Vida Activo Agresivo Destructivo con el Estilo de Vida Pasivo Regresivo Apelativo y del Estilo de Vida Pasivo Regresivo Apelativo con el Estilo de Vida Pasivo Regresivo Distanciado. Ver Tabla 4. 
TABLA 4. Localización del estilo de vida que plantea diferencias en las habilidades para la negociación en general

\begin{tabular}{|c|c|c|c|c|c|c|c|c|c|c|c|}
\hline $\begin{array}{l}\text { Comparación de } \\
\text { Diagnósticos }\end{array}$ & \multicolumn{2}{|c|}{ Casos } & \multicolumn{2}{|c|}{$\begin{array}{c}\text { Rango } \\
\text { Promedio }\end{array}$} & \multicolumn{2}{|c|}{$\begin{array}{c}\text { Suma de } \\
\text { Rangos }\end{array}$} & \multicolumn{2}{|c|}{$\begin{array}{c}\text { Media } \\
\text { Aritmética }\end{array}$} & \multirow{2}{*}{$\begin{array}{c}\mathrm{U} \\
502.5\end{array}$} & \multirow{2}{*}{$\begin{array}{c}\mathrm{Z} \\
-5.389\end{array}$} & \multirow{2}{*}{$\begin{array}{c}\mathrm{P} \\
0.000^{*}\end{array}$} \\
\hline $\mathrm{AAO}-\mathrm{AAD}$ & 268 & 17 & 149.63 & 38.56 & 40099.5 & 655.5 & 196.18 & 170.65 & & & \\
\hline AAO - PRA & 268 & 44 & 163.71 & 112.58 & 43874.5 & 4953.5 & 196.18 & 185.59 & 39.63 .5 & -3.485 & $0.000 *$ \\
\hline AAO - PRD & 268 & 14 & 144.7 & 80.04 & 38782.5 & 1120.5 & 196.18 & 179.93 & 1015.5 & -2.893 & $0.004 *$ \\
\hline AAD - PRA & 17 & 44 & 17.79 & 36.10 & 302.5 & 1588.5 & 170.65 & 185.59 & 149.5 & -3.613 & $0.000 *$ \\
\hline AAD - PRD & 17 & 14 & 14.26 & 18.11 & 242.5 & 253.5 & 170.65 & 179.93 & 89.5 & -1.172 & 0.241 \\
\hline PRA - PRD & 44 & 14 & 30.81 & 25.39 & 1355.5 & 355.5 & 185.59 & 179.93 & 250.5 & -1.046 & 0.296 \\
\hline
\end{tabular}

(*) $\mathrm{P}<0.05$

(**) $\mathrm{P}<0.01$

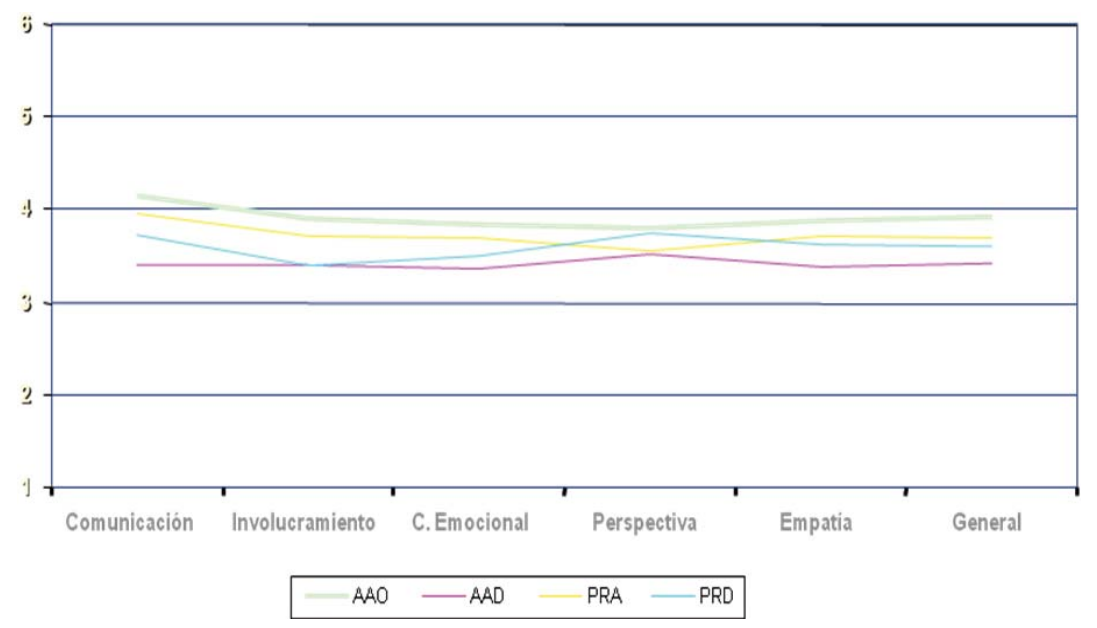

FIGURA 1. Descripción diagnóstica de las habilidades para la negociación según los estilos de vida.

\section{Las habilidades en general para la negociación según el nivel ocupacional}

La habilidad general para la negociación según el nivel ocupacional al contrastar los rangos promedio se ubica un valor Ji cuadrado por la que se expresa el análisis de Kruskal Wallis, 
de 28, 031 que para cuatro grados de libertad el Valor hallado tiene una probabilidad de ocurrencia de conformidad con la hipótesis de nula menor de 0.05 , razón por la cual se rechaza la hipótesis nula, confirmándose la hipótesis que afirma que las habilidades de negociación para la negociación difieren según los niveles ocupacionales, esto posiblemente por lo que implican que detrás de cada puesto, está la persona que responde a toda una historia de desarrollo personal.

\section{Las habilidades para la negociación en general según el nivel ocupacional}

Los resultados pueden verse en la Tabla 5, como se presenta:

TABLA 5. Localización del nivel ocupacional que plantea diferencias en las habilidades para la negociación en general

\begin{tabular}{lcccccccccccc}
\hline $\begin{array}{l}\text { Comparación del } \\
\text { nivel ocupacional }\end{array}$ & Casos & $\begin{array}{c}\text { Rango } \\
\text { Promedio }\end{array}$ & \multicolumn{3}{c}{$\begin{array}{c}\text { Suma de } \\
\text { Rangos }\end{array}$} & \multicolumn{2}{c}{$\begin{array}{c}\text { Media } \\
\text { Aritmética }\end{array}$} & U & Z & P \\
\hline Jefes - Prof. & 26 & 62 & 51.92 & 41.39 & 1350 & 2566 & 204.81 & 196.97 & 613 & -1.766 & 0.077 \\
Jefes - Admón. & 26 & 38 & 40.23 & 27.21 & 1046 & 1034 & 204.81 & 193.16 & 293 & -2.749 & $0.006^{*}$ \\
Jefes - Obr. Calif & 26 & 84 & 79 & 48.23 & 2054 & 4051 & 204.81 & 187.11 & 481 & -4.300 & $0.000^{*}$ \\
Jefes - Obr. Oper & 26 & 161 & 128.56 & 88.42 & 3342.5 & 14235.5 & 204.81 & 190.06 & 1194.5 & -3.509 & $0.000^{*}$ \\
Prof. - Admón. & 62 & 38 & 54.52 & 43.95 & 3380 & 1670 & 196.97 & 193.16 & 929 & -1.769 & 0.077 \\
Prof. - Obr. Calif & 62 & 84 & 89.67 & 61.57 & 5559.5 & 5171.5 & 196.97 & 187.11 & 1601.5 & -3.970 & $0.001^{*}$ \\
Prof. - Obr. Oper & 62 & 161 & 132.38 & 104.15 & 8207.5 & 16938.5 & 196.97 & 190.06 & 3727.5 & -2.928 & $0.003 *$ \\
Admón. - Obr. Calif & 38 & 84 & 69.42 & 57.92 & 2638 & 4865 & 193.16 & 187.11 & 1295 & -1.665 & 0.096 \\
Admón. - Obr. Oper & 38 & 161 & 106.53 & 98.46 & 4048 & 15852 & 193.16 & 190.06 & 2811 & -0.777 & 0.437 \\
Obr. Calif - Obr. Oper & 84 & 161 & 115.84 & 126.74 & 9730.5 & 20404.5 & 187.11 & 190.06 & 6160.5 & -1.143 & 0.253 \\
\hline
\end{tabular}

(*) $\mathrm{P}<0.05$

$(* *) \mathrm{P}<0.01$

A. En la habilidad general para la negociación, los valores $\mathrm{Z}$ son significativos aun para valores de P menores de 0.01 , en dirección de los Jefes, respecto a los profesionales, administrativos, obreros calificados y obreros operativos.

B. Los profesionales también presentan mayor habilidad para la negociación que los obreros.

C. Los administrativos no difieren de los obreros.

D. Se concluye que, a mayor responsabilidad implicada en el nivel ocupacional, dentro de la organización es mayor la habilidad de negociación para la gestión de conflictos. 


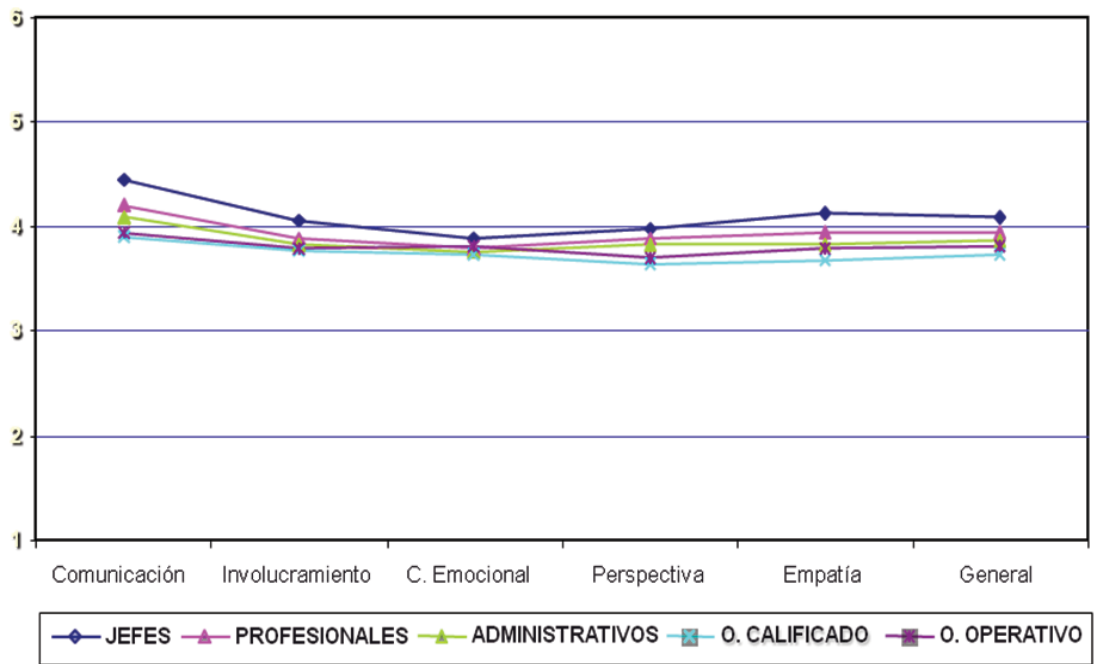

FIGURA 2. Descripción diagnóstica de las habilidades para la negociación según los niveles ocupacionales

Entre los factores de la habilidad para la negociación se ubica al factor control emocional de las habilidades para la negociación según Nivel ocupacional, que no plantea diferencia, ya que los valores $\mathrm{Z}$ son significativos mayores de valores $\mathrm{P}$ de 0.05 , razón por la cual no se pueda rechazar la hipótesis nula, afirmando que el control emocional no difieren en función al nivel ocupacional. Este resultado puede verse en la Tabla 6.

TABLA 6. Localización del nivel ocupacional que plantea diferencias en el factor de Control Emocional de las habilidades para la negociación.

\begin{tabular}{lcccccccccccc}
\hline $\begin{array}{l}\text { Comparación del } \\
\text { nivel Ocupacional }\end{array}$ & \multicolumn{2}{c}{ Casos } & \multicolumn{2}{c}{$\begin{array}{c}\text { Rango } \\
\text { Promedio }\end{array}$} & \multicolumn{2}{c}{$\begin{array}{c}\text { Suma de } \\
\text { Rangos }\end{array}$} & $\begin{array}{c}\text { Media } \\
\text { Aritmética }\end{array}$ & U & Z & P \\
\hline Jefes - Prof. & 26 & 62 & 46.83 & 43.52 & 1217.5 & 2698.5 & 38.77 & 37.90 & 745.5 & -0.556 & 0.578 \\
Jefes - Admin. & 26 & 38 & 35.33 & 30.57 & 918.5 & 1161.5 & 38.77 & 37.50 & 420.5 & -1.008 & 0.314 \\
Jefes - Obr. Calif & 26 & 84 & 62 & 53.49 & 1612 & 4493 & 38.77 & 37.30 & 923 & -1.193 & 0.233 \\
Jefes - Obr. Oper & 26 & 161 & 99.54 & 93.11 & 2588 & 14990 & 38.77 & 38.07 & 1949 & -0.564 & 0.573 \\
Prof. - Admin. & 62 & 38 & 52.78 & 46.78 & 3272.5 & 1777.5 & 37.90 & 37.50 & 1036.5 & -1.010 & 0.313 \\
Prof. - Obr. Calif & 62 & 84 & 79.42 & 69.13 & 4924 & 5807 & 37.90 & 37.30 & 2237 & -1.460 & 0.144 \\
Prof. - Obr. Oper & 62 & 161 & 113.10 & 111.58 & 7012 & 17964 & 37.90 & 38.07 & 4923 & -0.158 & 0.874 \\
Admin. - Obr. Calif & 38 & 84 & 62.96 & 60.84 & 2392.5 & 5110.5 & 37.50 & 37.30 & 1540 & -0.308 & 0.758 \\
Admin. - Obr. Oper & 38 & 161 & 93 & 101.65 & 3534 & 16366 & 37.50 & 38.07 & 2793 & -0.836 & 0.403 \\
Obr. Calif - Obr. Oper & 84 & 161 & 113.76 & 127.82 & 9555.5 & 20579.5 & 37.30 & 38.07 & 5985.5 & -1.479 & 0.139 \\
\hline
\end{tabular}

(*) $\mathrm{P}<0.05$

(**) $\mathrm{P}<0.01$ 


\section{DISCUSIÓN}

A partir de los resultados se encuentra que hay diferencias en las habilidades de negociación según el estilo de vida y el nivel ocupacional. Al respecto, se infiere en concordancia a lo expuesto especialmente por la UNESCO (2009), OMS y OIT, que las habilidades para la vida que una persona requerirá en un momento y contexto específico varían enormemente dependiendo entre otras variables, del área de actividad, el contexto social y cultural, el grupo etario, así, se observa entre los recursos personales para la vida, las habilidades interpersonales para la negociación que cualifican la posición desempeñada en la jerarquía organizacional.

Habilidades corroboradas en el trabajo de campo, presentan diferencias según el nivel ocupacional que vienen desempeñando los colaboradores de las organizaciones productivas del estudio, es decir, ellos han desarrollado o aprendido en el proceso demando por cada tarea la habilidad de negociación en concordancia a la exigencia de la labor en la organización; aprendizaje adquirido mediante su entrenamiento y la exposición en su nivel ocupacional, el que ha marcado diferencias en dicha habilidad. En tanto la ejecución de la actividad del trabajo forma la personalidad y la ideología, Rubinstein (1967), se tiene en el caso de las habilidades para la negociación, del nivel ejecutivo obtiene mayores valores que los profesionales, administrativos y obreros tanto calificados como los operativos, por la responsabilidad de ser el modelo por su posición en el proceso de aprendizaje y por las exigencias y señalamientos expresas en las normas de gestión de la calidad empresarial.

Así mismo, en la población del estudio, están acuñando su Estilo de vida, que va fortaleciéndose por la capacidad del individuo, según Adler, debido a la condición de la modificabilidad del estilo de vida, en interacción con el ambiente de trabajo que construye la organización. La tendencia del complejo medio-fin ya sea el activo agresivo o el pasivo regresivo será influida o condicionada por su entorno en medidas diferentes, sea por ejemplo por los recursos como la infraestructura, equipos como sistemas de información, tanto como las normas y pautas de las conductas organizacionales, las circunstancias de la convivencia laboral, el clima organizacional sustentada en la cultura organizacional. De ahí que se explique que las habilidades interpersonales presenten diferencias significativas por el Estilo de vida, identificándose que son mayores el Activo Agresivo Objetivo y Pasivo Regresivo Apelativo, que los otros dos estilos de vida. También es puesto de relieve por la investigación de Beersma Ten Velden y De Dreu (2007), en la que el alejamiento de la tendencia proself, propio del estilo de vida Activo Agresivo Destructivo (Titze) conduce al fracaso en la negociación Yo gano - tú ganas, y genera una escalada hacia la obtención del poder.

Un elemento que condicionaría en alguna medida la habilidad para la negociación lo constituye la toma de decisiones en entornos de incertidumbre ante los riesgos que implican. Esto guarda relación con el hecho de que al realizarse el análisis independientemente por variables, se encuentra que los ejecutivos presentan una mayor habilidad de comunicación para la negociación entre los diferentes niveles ocupacionales de la jerarquía organizacional. Para ello el ejecutivo ha de ser una persona cuya personalidad ofrece disposición a tratar con los clientes internos y externos en forma permanente, ocupándose de proveerlo de los medios para desempeñar su trabajo. Un ejecutivo sin subalternos directos como obreros 
calificados o no, es un ser inexistente en la jerarquía organizacional. En cambio, se presume por los resultados que un obrero ante su máquina requiere para su trabajo de otras habilidades, y menos vinculadas con la negociación, especialmente en tareas que requieran una frecuente interacción interpersonal con los usuarios o aquellas estandarizadas o líneas en serie de producción o identificadas como monótonas, por tanto puede ser un activo agresivo destructivo e incluso un pasivo regresivo distanciador con rasgos esquizoides no sería un caso desequilibrante; ello no desdice que dicho nivel ocupacional requiera de habilidades para la negociación por la naturaleza social del trabajo en vías de lograr la negociación como norma de la cultura organizacional.

Del mismo modo, una característica del Estilo de vida que se manifiesta en la forma de diferencia en las habilidades de comunicación como una de las habilidades de negociación; se le ha encontrado que en el tipo Activo agresivo objetivo logra un mayor promedio, acuñada e incorporada en su estrategia aprendida en concordancia a su perfil que lo describe, el de valerse del diálogo y la comunicación para solucionar problemas, en tanto que en el extremo opuesto, el promedio más bajo lo obtiene el tipo Activo Agresivo Destructivo, quien para solucionar problemas lo hará mediante o empleará la fuerza y la imposición.

Además, referido al mismo punto, se considera importante el aporte de Curhan y Pentland (2007), quienes demostraron el nivel de actividad de la participación de un compromiso en la conversación, el énfasis prosódico, y de modo paralelo vocales percibidas como "actuaciones sutiles" en los 5 minutos iniciales en una conversación en una mesa de negociación tiene injerencia en el otro, lo que permite aunar que, quien trasmite mayor seguridad tiene influencia en los resultados, así el Activo agresivo objetivo tiene mayor estabilidad como característica del Estilo de vida, marcando así la diferencia del factor habilidad de comunicación para la negociación, al igual por el nivel ocupacional, siendo a favor un mayor promedio el ejecutivo que los otros niveles .

Estaríamos así, cuando hay disposición real para la comunicación ante una forma más de ser dada por el Interés social, pues no es sólo la necesidad de comunicarse, sino que está orientada hacia el diálogo como medio de solución de conflictos, con una expresa evitación del uso de la fuerza, concebida y sentida, por ser perpetuadora o generadora del conflicto. En este punto, A. Adler apuesta por la opción Yo gano - tú ganas. La comunicación parte de la definición de la negociación, según Ury y Fischer (1991).

El factor de compromiso o habilidad de involucramiento para la negociación según el estilo de vida plantea diferencias, es una característica, según Adler, de la persona activa y se manifiesta cuando se centra el interés social comunitario, él se refiere a la responsabilidad social de la organización o empresa como factor básico que tiene en cuenta o le posibilita para tomar la decisión en vías de la solución del conflicto. La tipología de Estilo de vida propio de activo agresivo objetivo, es la más orientada a asumir y cumplir compromisos, ya que es el que tiene más desarrollado el interés social o sentimiento de comunidad en el que se antepone la tarea por el bien común a otros intereses.

Se presenta también diferencias de la habilidad de compromiso para la negociación según el nivel ocupacional, siendo el grupo de ejecutivos quienes alcanzan un mayor promedio que los otros; se entiende que el nivel ejecutivo logre mayor compromiso en tanto que, él es el que comanda y que no sólo ejecuta las políticas en concordancia con el planeamiento 
estratégico, sino que tiene injerencia directa en revalorar la visión y misión que tienen las empresas productoras. Desde la perspectiva de la administración funcional (Parsons, Talcott), este es el nivel que le compete movilizar y coordinar los esfuerzos, competencias, recursos de los integrantes de los niveles inferiores o subordinados hacia el logro de los objetivos, aunando esfuerzos para que al nivel institucional cumpla su responsabilidad empresarial, concordando así con el modelo de Tavistock, que para cumplir con el Subsistema Social de la Empresa, se requiere indudablemente tener muy alta la habilidad de involucramiento para negociar.

Pero, además de que el factor del compromiso también está presente en las negociaciones exitosas, como lo demuestran Curhan y Pentland (2007), el poder lograr en el otro el compromiso en la problemática del objeto de negociación, se señala que viene ser una condición per se la habilidad de negociación en su factor involucramiento, o ser desarrollada para obtener competencias y responder entre las responsabilidades del ejecutivo, el involucrar a sus subordinados o seguidores.

En el Factor Control Emocional de la habilidad para la negociación, se observa que plantea diferencias con el Estilo de vida, logrando un mayor promedio el tipo Activo agresivo objetivo y el menor el Activo agresivo destructivo, de tal manera se evidencia también se pone de manifiesto el papel del Estilo de Vida, aunque no se dé para marcar diferencias entre los grupos ocupacionales. Los datos que confirman presumir que las estrategias acuñadas por el Estilo de vida adquiridas en el proceso de socialización en la organización varia por el aprendizaje previo de los actores antes de la actividad de la tarea; ya que no se presenta para el caso de la variable independiente asignada, nivel ocupacional, puesto que ella plantea que no existen diferencias significativas en la habilidad de control emocional para negociar. Siendo notoria la ausencia de diferencias entre los cinco niveles ocupacionales en el factor control emocional de las habilidades para la negociación, factor inherente a la estructura o componente de la personalidad que se va estructurando desde el nivel de neonato, y concuerda con las teorías del desarrollo que le otorgan la importancia al contexto para los infantes en la edad pre escolar, escolar prioritariamente antes de los 9 años, y a ser cimentada en las grupos secundarios, primeramente la institución educativa, para la solidez en la adultez por la exploración y confrontación en la adolescencia.

Dicho resultado del factor de Control emocional para la negociación orienta a confirmar, que a pesar de la socialización en la organización productiva y a los grados saludables del logro del coeficiente emocional (Baron, en Goleman, 1996) que tenga una persona, sus emociones al tener un componente fisiológico escapa al control racional y social, es decir la emoción está vinculada a otros factores o proceso psicológicos, especialmente a la naturaleza psicobiológica de la personalidad; alcances teóricos compatibilizan con los datos empíricos que describen que en todos los niveles ocupacionales de las empresas productoras, esta habilidad se comporta similarmente; así por ejemplo el nivel Ejecutivo y el Obrero (operario sin calificación) alcanzan un promedio similar.

El factor Perspectiva de la habilidad para la negación plantea diferencias según el Estilo de vida, así como según el nivel ocupacional, habilidad que posibilita a los actores de las empresas productoras colocarse prospectivamente en escenarios futuros que posibilite rentabilidad frente al otro, a partir de un dato, indicador, señal observable llega a tener 
una visión o interpretación integral o total. Desde la perspectiva teórica empleada estamos frente al dominio de la actividad en cuanto a dar los pasos para alcanzar una meta, en la que también interviene el proceso educativo, al brindar estrategias y ensayos de planeación que son plenamente manifiestos cuando se produce el desempeño profesional.

Prueba de ello es que hay diferencias entre los Estilos de vida, activo agresivo objetivo y el pasivo regresivo, el primero lo hace enfrentándose directamente a fin de lograr objetivos antes que perseguir ganancias secundarias, en cambio el pasivo regresivo distanciador retrocede frente a los problemas y se apresta a elaborar síntomas o excusas de evasión, llegando al retraimiento ante su contrincante como camino aprendido para lograr sus metas, probablemente usando su falta de capacidad como medio de afronte a sus problemas, de los cuales tampoco espera solución.

Del mismo modo, se ha encontrado que el Estilo de vida y los niveles ocupacionales plantean diferencias en el factor empatía de la habilidad para la negociación en los actores de las empresas productoras; lo cual es esperable debido al carácter socializante del Activo agresivo objetivo, quien supera al Pasivo regresivo apelativo; teniendo ambos estrategias e intereses opuestos, el primero se dirige a la sociedad, y a ponerse del lado del otro, y el segundo usa mecanismos y tácticas de lograr la atención de quienes le rodean sin importarle el costo individual y grupal de las acciones efectuadas, es decir lo que se conoce como ególatras y egoístas.

Los resultados tienden a confirmar el rol preponderante del aprendizaje en los contextos familiares, educación y laboral para el desarrollo de las habilidades sociales, así la realidad socioeducativa y cultural habrían posibilitado que los actores a nivel ejecutivo, directivo o jefe demuestren un mayor nivel en habilidades para la negociación seguidos del nivel profesional o técnico de las empresas productoras en el Factor de empatía de las habilidades para negociación. Futuras investigaciones podrán tener en cuenta el papel del proceso formativo, tanto en años como en contenidos con respecto a estas habilidades. La conexión a que se presente se refiere a la afirmación de Adler de la modificabilidad del estilo de vida, como producto de los aprendizajes derivados de las interacciones, a la manera de un mecanismo de corrección tanto de la trayectoria como de la meta, al incrementarse el interés social.

También en relación con el aprendizaje, O'Connor y col. presentan una opción de investigación no cubierta en la presente tesis, consistente en el efecto de las experiencias previas de negociación, tal abordaje no se hizo porque corresponde a una investigación experimental, los autores encuentran que el resultado previo en una negociación es repetido por el negociador pero encuentra una excepción cuando hay un cambio de socio, y dentro del abordaje que se sigue, es importante notar que habría influencia por parte de la persona coparticipante, lo cual nos lleva a inferir que la variable personalidad interviene activamente, siendo susceptible de atribuirlo al complejo medios-fin.

En referencia al tema de las habilidades interpersonales para la negociación, según plantean los Estilos vida, se ha confirmado los supuestos planteados por Adler, descritos por Titze (1983), Vicuña y col. (2000) en relación a que los Estilos de vida, así se ha encontrado las diferencias significativas teniendo en su núcleo central los Complejos Medio-fin, del Activo agresivo objetivo con el Pasivo regresivo apelativo y Pasivo regresivo distanciador. 
El primero enfrentando la realidad empleando los factores de control emocional, empatía, comunicación, perspectiva e involucramiento de la habilidad para la negociación.

Los resultados generales de las habilidades interpersonales para la negociación según el nivel ocupacional, plantean diferencias significativas según el Estilo de vida, confirmación empírica válida a la luz de la lógica y las teorías del enfoque de las contingencias, así como las normas de calidad, y que conllevan a que la manera de lograr el cambio y fomentar climas organizacionales saludables parten del nivel gerencial o directivos, como competencias de los ejecutivos, así como la responsabilidad de los profesionales, lo cual nos lleva a pensar que son fortalezas inherentes a empresas productoras, como las que han colaborado con el estudio ya que están ranqueadas como excelentes en su respectivo mercado.

\section{CONCLUSIONES}

Las habilidades interpersonales para la negociación difieren según los Estilos de vida adquiridos.

Los niveles ocupacionales, excepto en la de control emocional, plantean diferencias según las habilidades interpersonales de negociación.

Por tanto, la habilidad interpersonal para la negociación difiere según los Estilos de vida y el nivel ocupacional de la población de empresas productoras en el Perú.

Específicas:

1. Las habilidades para la negociación son significativamente mayores en los Estilos de vida: Activo Agresivo Objetivo y en el Pasivo Regresivo Apelativo que en los otros estilos.

2. La habilidad interpersonal para la negociación en la población de empresas productoras en el Perú difiere entre el estilo de vida Activo Agresivo Objetivo y el estilo de vida Pasivo Regresivo Apelativo, superando el estilo Activo Agresivo Objetivo (AAO) al Pasivo Regresivo Apelativo (PRA).

3. La habilidad interpersonal para la negociación de la población de empresas productoras en el Perú con estilo de vida Activo Agresivo Objetivo es mayor que el estilo de vida Pasivo Regresivo Apelativo.

4. La habilidad interpersonal para la negociación de la población de empresas productoras en el Perú con estilo de vida Activo Agresivo Objetivo supera al estilo de vida Pasivo Regresivo Distanciador

5. La habilidad interpersonal para la negociación de la población de empresas productoras en el Perú con estilo de vida Activo Agresivo Objetivo es mayor que el estilo de vida Pasivo Regresivo Distanciador.

6. La población de empresas productoras en el Perú con estilo de vida Pasivo Regresivo Apelativo supera en la habilidad interpersonal para la negociación a la población de Estilo de vida Activo Agresivo Destructivo. 
7. No existe diferencia en la habilidad interpersonal para la negociación de la población de empresas productoras en el Perú de estilo de vida Activo Agresivo Destructivo con la de estilo de vida Pasivo Regresivo Distanciador.

\section{RECOMENDACIONES}

1. Se plantea incluir la negociación como un factor significativo en el estudio del clima organizacional y cultura organizacional, como una estrategia para la solución de conflictos.

2. Se propone incluir en el perfil psicoprofesiográfico las habilidades interpersonales para la negociación, entre los indicadores de diagnóstico para la gestión de los recursos humanos.

3. Incluir el Estilo de Vida Activo Agresivo objetivo con un indicador significativo para el pronóstico en la negociación eficiente.

4. Replicar estudio en pymes y replicar el estudio a nivel de estudiantes universitarios.

\section{NOTA DE RECONOCIMIENTO}

Mi especial reconocimiento a la colaboración de los participantes, miembros y trabajadores de las empresas: AMFAVITRUM S.A.; Laboratorio Farmacéutico Unido (LUSA); Metal Metálica (HAUG); y AJEPER S.A. Y a cada uno de los que hicieron posible la culminación de la tesis, a la Dra. Lupe García A, Asesora, Dr. Luis Vicuña P., por sus aportes metodológicos, Dr. Alejandro Loli P. y Nicolás Medina en calidad de jurados.

\section{REFERENCIAS BIBLIOGRÁFICAS}

1. Adler, A. (1938). El sentido de la Vida. Santiago de Chile: Colección "Hombres e Ideas". Editorial Cultura, Casilla 4130

2. Alcover de La Hera, C. Ma. (2000). "Sobre la progresiva-Cognitivización-de la psicología de los grupos: una revisión de la aplicación de constructor cognitivos a nivel grupal”. Facultad de Ciencias Juritas y Sociales. Universidad Rey Juan Carlos, Madrid. En La mirada psicosociológica: Grupos, procesos, lenguaje y culturas. Madrid: Editores Domingo Caballero, María Teresa Méndez \& Juan Pastor. Biblioteca Nueva.

3. Argyris, C. (1993). Como Vencer las Barreras Organizativas. Madrid: Ediciones Díaz de Santos S.A.

4. Antonioni, D. (1998). Relationship between the big five personality factors and conflict management styles. International Journal of Conflict Management, Vol. 9, 336-355.

5. Burns, T. \& Stalker, G. (1994). The management of innovation. Oxford: University Press. Third edition. 
6. Caballo, V. (1999). Manual de evaluación y entrenamiento de habilidades sociales. 3. ${ }^{\text {a }}$ ed. Madrid: Siglo XXI de España Editores S.A.

7. Chandler, A. (2003). Strategy and Structure: Chapters in the History of the American Industrial Enterprise. Washington: MIT.

8. Córdova, J. E. (1990). Economía. Lima: Editorial Universitaria San Martín de Porres.

9. Cronbach, L. (1972). Fundamentos de la Exploración Psicológica. 2. ${ }^{\text {a }}$ ed. Madrid: Biblioteca Nueva.

10. Curhan, J. \& Pentland, A. (2007). Thin Slices of Negotiation: Predicting Outcomes From Conversational Dynamics Within the First 5 Minutes. Journal of Applied Psychology, vol. 92(3): 802-811.

11. Chruden, H. J. \& Sherman, Jr. A. (1979). Administración de personal. 5. a ed. México: Compañía Editorial Continental, S.A.

12. Etkin, J. R. (1994). La doble Moral de las Organizaciones: Sistemas perversos y la corrupción institucionalizada. Madrid: Editorial McGraw Hill.

13. De Miguel, J. Ma. \& Cordero, C. (2001). "La Organización como construcción Social. Perspectiva Psicosocial". Revista de la Facultad de Psicología de la Universidad Nacional Mayor de San Marcos. Año V (1-2), 55-88.

14. De Miguel, J. Ma. (1999). La Organización como construcción social Representación organizacional. Tesis Doctoral, Universidad Autónoma de Madrid, Facultad de Psicología, Dpto. Psicología Social y Metodología. España.

15. Diccionario Enciclopédico Quillet en Ocho tomos (1968).T. III. Buenos Aires: Editorial Argentina, Arístides Quillet, S.A.

16. Daft, R. (2005). Teoría y diseño organizacional. México: Thomson Ediciones.

17. Entelman, R. (2002). Teoría de Conflictos. Barcelona: Editorial Gedisa S.A.

18. Flint, P. (2003). Negociación Integral, Herramienta eficaz para la Resolución de Conflictos y la Creación de Valor. Cómo negociar y conciliar para resolver conflictos. Lima: Editora Jurídica Grijley.

19. García, E. (2003). El arte de relacionarse. Málaga: Ediciones ALJIBE.

20. Grañeras, M. \& Parras, A. (2008). Orientación educativa: fundamentos teóricos, modelos institucionales y nuevas perspectivas. España: Ministerio de Educación, Política Social y Deporte Subdirección General de Información y Publicaciones.

21. Gordon, J. (1997). Comportamiento Organizacional. México: Prentice.

22. Goleman, D. (1996). Inteligencia Emocional. Barcelona: Editorial Cairos.

23. Guilford, J. (1986). La Naturaleza de la Inteligencia Humana. Barcelona: Paidos.

24. Hellriegel, D. \& Slocum, J. Jr. (2009). El manejo del conflicto interpersonal y la negociación. En Comportamiento Organizacional. México: Editorial Thomson, pp. 224-246. 
25. Hernández, R. Fernández-Collado, C. \& Baptista, L. (2007). Metodología de la investigación. México: McGraw Hill.

26. Hernández, R. Fernández-Collado, C. \& Baptista, L. Pilar (1997). Metodología de la investigación, México: McGraw Hill.

27. Jacobsen, J. (1983). Principios y Métodos del Trabajo de Extensión. Tejnión - Instituto Israelí de Tecnología, Haifa. Israel: Edición Jerusalén.

28. Katz, D. \& Kahn, R. (1995). Psicología Social de las organizaciones. México: Trillas.

29. Katona, G. (1965). Análisis del comportamiento Económico. Buenos Aires: Ateneo.

30. Kerlinger, F., \& Lee, H. (2002). Investigación del Comportamiento. Métodos de Investigación en Ciencias Sociales, México: McGraw Hill.

31. Kriesberg, L., (1975). Sociología de los conflictos sociales. México D.F.: Trillas.

32. Lapassade, G. (1977). Grupos, Organizaciones e Instituciones. Barcelona: Granica Editor S.A.

33. Luthans, F. (2008). Comportamiento Organizacional. México D.F.: McGraw Hill / Interamericana Editores, S.A.

34. Luthans F. \& Kreitner, Rt. (1989). Modificación de la conducta organizacional. México: Trillas.

35. McClelland, D. \& Winter, D. (1970). Cómo se motiva el éxito económico. México: Centro Regional de Ayuda Técnica. AID.

36. Madsen, K. B. (1967). Teorías de la Motivación. Un estudio comparativo de las teorías modernas de la motivación. Buenos Aires: Paidos.

37. Miner, J. (2007). Organizational Behavior 4 From Theory to Practice. N.Y.: Publisher M.E. Sharp Inc.

38. Montero, M. \& col. (1980) Psicología Social. México D.F.: Trillas.

39. Morales, J. \& Jiménez, S. (1999). El grupo y sus conflictos. España, Ediciones de la Universidad de Castilla-La Mancha Series, Vol. 29 de la Colección Humanidades N. ${ }^{\circ} 29$.

40. Oberst, U. (1998). El trabajo terapéutico con sueños: una aproximación adleriana-constructivista. Revista de Psicoterapia Vol. 34-35: 137-150.

41. Oberst, U. \& Stewart, A. (2004). Adlerian Psychotherapy. An Advanced Approach to Individual Psychology. Londres: Brunner-Routledge.

42. O'Connor, K., Arnold, J. \& Burris, E. (2005). Negotiators' Bargaining Histories and Their Effects on Future Negotiation Performance. USA, Journal of Applied Psychology, Vol. 90 (2), 350-362.

43. Ogier, T. (2009). Habilidades para competir en la Educación post secundaria y sustentabilidad comercial en América Latina. Informe de Economist Intelligence Unit. Editora Door, K. Abreu. 
44. Paredes, M. \& De Miguel, J. Ma. (2004). Construcción Social de la Comunidad para el Desarrollo del Callejón de Huaylas, Caraz. Revista de Investigación en Psicología, Instituto de Investigaciones Psicológicas, Facultad de Psicología. UNMSM. Vol. 7(1), 81-102.

45. Paredes, M. (1997). La Interdependencia Empresarial Factor de Calidad en la Gestión - Caso Sector Empresarial Pesquero Peruano. Tesis de Magíster, Universidad Nacional Mayor de San Marcos, Escuela de Post Grado, Unidad de Post Grado de la Facultad de Ciencias Administrativas, Lima.

46. Paredes, M. (2004). Gestión de Calidad y Principios de Administración en Psicología Científica: Enfoque y Temas actuales Contribuciones al Curso de Actualización y Preparatorio de la Maestría en Psicología. UNMSM - UPG de Psicología.

47. Parsons, T. (1960). Structure and Process in Modern Societies. USA, Glencoe III, Free Press.

48. Peiró, J. Ma.; Prieto, F. \& Roe, Rt. (1996). La Aproximación Psicológica al Trabajo en un entorno Laboral Cambiante; en Tratado de Psicología del Trabajo Volumen I: La actividad laboral en su contexto. España: Editorial Síntesis, S.A.

49. Pfeffer, J. (1992). Organizaciones y teoría de las organizaciones. México: Fondo de Cultura Económica.

50. Piaget, J. \& Inhelder, B. (1969). Psicología del Niño. Madrid: Ed. Morata.

51. Pili, G. (1972). Tecnología y Cultura. Suplementos 14 Textos de la Historia Social del Pensamiento ANTHROPOS Revista de Documentación Científica de la Cultura 126-138. Tecnología, Ciencia, Naturaleza y Sociedad. Antología de Autores y Textos por el Instituto de Investigaciones Sobre Ciencia y tecnología. Barcelona, Kranzberg y H.H. Davenport (ed.).

52. Pulido, C. (2000). Construcción, Validación y Aplicaciones de una Prueba que mida el Clima Organizacional en Organizaciones Empresariales Privadas y su Implicación para la Psicología de la Salud. Tesis para optar el Grado de Magíster en Psicología mención Psicología Clínica UNMSM / Escuela de Post Grado / Facultad de Psicología Unidad de Post Grado. Lima.

53. Rivera, J. (1996). Psicofísica. Separata del Curso de Psicología de la Percepción. Lima: UNMSM - FP.

54. Robbins, S. (1994). Comportamiento Organizacional. Conceptos, Controversias y Aplicaciones. México: Pretince Hall.

55. Ruiz, J. (2004), Glosario de 40 Términos Adlerianos.En: http://www.cop.es/ colegiados/GR00724/adler/ADLER-7.html

56. Ruiz Sánchez, J. \& col. (2001). Trabajando los sueños Interpretaciones en Psicoterapiahttp://www.psicologia-online.com/ESMUbeda/Libros/Suenos/suenos.htm

57. Rubinstein J. L. (1967). Principios de Psicología General. México D.F.: Editorial Grijalbo, S.A. 
58. Santoro, E. \& col. (1980). Psicología Social. México D.F.: Trillas.

59. Sheriff, M. \& Sheriff, C. (1974). Psicología social. México D.F.: Harla.

60. Shulman, B. (1985). La terapia cognitiva y la psicología individual de Alfred Adler. En Mahoney, M. J. \& Freeman, A. (1988) Cognición y psicoterapia. Barcelona: Ed. Paidós.

61. Simons, H. (1964). El comportamiento Administrativo. Madrid: Editorial Aguilar.

62. Solf, A. (2004). Tesón y Orientación de Meta como elementos del Modelo Motivacional de Hachman y Oldham. Tesis para optar el grado académico de Magister en Psicología, Mención en Psicología Organizacional. UNMSM/ Escuela de Post Grado / Facultad de Psicología UPG. Lima.

63. Tamayo, A. (2000). Valores de la organización versus valores de los empleados: una relación conflictiva. Universidad de Brasilia. En La mirada psicosociológica: Grupos, procesos, lenguaje y culturas. Madrid: Editores: Domingo Caballero, María Teresa Méndez y Juan Pastor.

64. Ten Velden, F.; Beersma, B. \& De Dreu, C. (2007). Majority and Minority Influence in Group Negotiation: The Moderating Effects of Social Motivation and Decision Rules. Journal of Applied Psychology, January 2007 Vol. 92(1), 259-268.

65. Titze, M. 1983. Fundamentos del Teleoanálisis Adleriano. Barcelona.

66. United National Educational, Scientif and Cultural Organization (UNESCO) (2009). Informe de seguimiento de la educación en el mundo "Superar la desigualdad: por qué es importante la gobernanza".

67. Urbano, D. \& Toledano, Na. (2008). Invitación al emprendimiento: una aproximación a la creación de empresas. España: Editorial UOC - Economía y Empresa.

68. Ury, W. y Fischer, R. 1991, “Si de acuerdo”. Editorial Norma, Bogotá, 5ta. Reimpresión.

69. Vicuña, L.; Hernández H.; Paredes, M. \&Ríos, J. (2008). Elaboración del test de habilidades para la negociación de conflictos. Revista de Investigación en Psicología, Instituto de Investigaciones Psicológicas, Facultad de Psicología. UNMSM. Vol. 11(2), 183-200 Lima.

70. Vicuña, L.; Paredes M.; Hernández, H \& Solís, R. (2000). Relación entre los Complejos Medio-Fin con los tipos de afronte ante la crisis económica. Revista de Investigación en Psicología, Instituto de Investigaciones Psicológicas, Facultad de Psicología. UNMSM. Vol. 3(1), 95-114.

71. Vicuña, L. (1991). Manual de Inventario de Intereses Profesionales y Ocupaciones. CSM-84-R91. Lima.

72. Webb, R. \& Fernández Baca, G. (2004). Anuario estadístico: Perú en números 2004. Lima: Instituto Cuánto.

73. Vroom, V. \& Deci, E. (1999). Motivación y Alta Dirección. México: Trillas. 